\begin{tabular}{|c|c|c|}
\hline $\begin{array}{l}\text { EXCELLENT } \\
\text { PUBLISHERS } \\
\end{array}$ & $\begin{array}{c}\text { International Journal of Current Research } \\
\text { and Academic Review } \\
\text { ISSN: 2347-3215 (Online) } \\
\text { Journal homepage: http://www.ijcrar.com }\end{array}$ & \\
\hline
\end{tabular}

doi: https://doi.org/10.20546/ijcrar.2017.511.003

\title{
Antimicrobial Activity of Lactic Acid Bacteria against Toxigenic Fungi
}

\author{
Wadad M. Al-Haik ${ }^{1}$, Ali Mohammed Abdullah Bawazir ${ }^{2}$, Magda Mohammad Aly ${ }^{3}$, \\ Ahmed M. Al-Haddad ${ }^{4}$ and Manjula Shantaram ${ }^{5 *}$
}

${ }^{I}$ Department of Biology, Faculty of Science, Hadhramout University, Al-Mukalla, Yemen

${ }^{2}$ Dept. of Microbiology, Mangalore University, Post Graduate Centre, Chikka Aluvara, Kodagu, Karnataka, India

${ }^{3}$ Department of Biology, Faculty of Science, King Abdul Aziz University, Jeddah, Saudi Arabia

${ }^{4}$ Department of Medical Laboratories, College of Medicine and Health Sciences, Hadhramout University, Al-

Mukalla, Yemen

${ }^{5}$ Department of Studies in Biochemistry, Mangalore University, Post Graduate Centre, Chikka Aluvara, Kodagu, Karnataka, India

*Corresponding author email id: manjula59@gmail.com

\begin{abstract}
Lactobacillus bulgaricus $S_{2}$ was widely used in fermentation and preservation of food and it was assayed on their fungal inhibitory properties. The aim of this study was to isolate lactic acid bacteria from different habitats and screen these isolates against some mycotoxigenic fungi. The effect of lactic acid bacteria (LAB) on growth of a mycotoxin- producing toxigenic fungi was assayed. Assays were carried out by modified overlay method. Lactobacillus bulgaricus $\mathrm{S}_{2}$ assays showed growth inhibition of the mycotoxin-producing Aspergillus flavus. Lactobacillus bulgaricus $\mathrm{S}_{2}$ isolated from sheep milk and selected for its technological properties, showed highest fungal inhibition of the micro-organisms assays. The use of antifungal LAB with excellent technological properties rather than chemical preservatives would enable the food industry to produce organic food without addition of chemical substances.
\end{abstract}

\section{Article Info}

Accepted: 28 October 2017

Available Online: 20 November 2017

\section{Keywords}

Antimicrobial activity,

Lactic acid bacteria,

Lactobacillus bulgaricus,

Toxigenic fungi.

\section{Introduction}

Molds and yeasts cause major problems in food and feed as spoilage organisms. They are particularly important because they produce mycotoxins (Pitt and Hocking, 1997). Bio-preservation, the use of microorganisms to preserve food and feed, has been considered as an alternative to the use of chemical preservation in the expectation that they could be safer (Strom et al., 2002).

Lactic acid bacteria (LAB) are a broad group of Gram positive, catalase-negative, non-spore forming rods and cocci, usually non-motile, that utilize carbohydrates or fermented and form lactic acid as the major end product (Aguirre and Collins, 1993). With occasional exception, they are aero-tolerant anaerobes. Lactic acid bacteria are widely distributed in several raw materials (milk, meat and flour), soil, silage and waste products (Holzapfel et al., 2001)

Most representatives of $\mathrm{LAB}$ do not pose any health risk to man and are designated as "Generally Recognized as Safe" (GRAS). They have commonly been used as a starter culture and play an essential role in manufacturing 
of a wide variety of fermented food such as curd, cheese, yoghurts, dry sausages, beers and sour doughs (Singh and Prakash, 2009).

Lactic acid bacteria (Lactobacillus fermentum and Lactobacillus rhamnosus) and Saccharomyces cerevisiae showed growth inhibition of the mycotoxin-producing Aspergillus. L. rhamnosus O236, isolated from sheep milk and selected for its technological properties, showed the highest fungal inhibition of the microorganisms assays (Muñoz et al., 2010). The LAB isolated from five indigenously fermented cereal gruels inhibited at least one aflatoxin-producing fungal isolate to varying extents (Onilude et al., 2005).

Magnusson et al., reported that Lactobacillus coryniformis subsp. Coryniformis strain Si3 produced proteinaceous compounds with a broad spectrum inhibitory action against several molds such as Aspergillus fumigatus, A. nidulans, Penicillium roqueforti, Mucorhiemalis, Talaromyces flavus, Fusarium poae, F. graminearum, F. culmorum and $F$. sporotrichoides (Magnusson et al., 2003).

Various mechanisms have been suggested to be responsible for the inhibitory effects of the bacteria on fungal growth, such as nutritional competition, secondary metabolites, $\mathrm{pH}$ or combinations of these mechanisms (El-Nezami et al., 2002). The inhibitory activity towards molds could be considered a characteristic for the selection of LAB used as starter cultures in grain ensiling of animal food in order to prevent avian fungal infection (Muñoz et al., 2010).

The aim of this study was to isolate lactic acid bacteria from different habitats and screen these isolates against some mycotoxigenic fungi. The effect of L. bulgaricus $\mathrm{S}_{2}$ was assessed with excellent industrial and health properties on growth, cell morphology and aflatoxins production of $A$. flavus.

\section{Materials and Methods}

Twenty-one bacteria were isolated from human milk, sheep milk, yoghurt, pasteurized milk and fermented food "pickles". All isolates of LAB were selected and purified on De Mann, Rogosa and Sharpe (MRS) medium after incubation for 48 hours at $30^{\circ} \mathrm{C}$ and $\mathrm{pH} 6$.

All isolates of LAB were screened for antimicrobial activity against Aspergillus niger, Penicillium sp., A. flavus, Aspergillus ochraceus and Fusarium sp. using modified overlay method that described by Magnusson and Schnurer (2000). The inhibitory effect was determined on plates using an overlay technique; the potentially inhibitory microorganisms were inoculated first on solid agar (using MRS media) and then test fungi was inoculated on top (with soft PDA media).

The maximum antifungal activity of the isolates in this study was selected and identified to genus level initially by morphological and physiological tests and according to Bergey's Manual of Systematic Bacteriology (Holt et al., 1994; Sharpe et al., 1979)

Effect of the active material on aflatoxins production of A. flavus was studied using thin-layer chromatography (TLC) and Chromato-Vue Cabinet (Model CC- 60, UVP Inc, an Gabried, California) under visible light or short wavelength UV light (254 nm) and long wavelength (366 $\mathrm{nm})$.

\section{Results and Discussion}

Only twenty-one bacterial isolates were obtained from the normal habitats of lactic acid bacteria. Seven bacterial isolates were obtained from human milk, whereas 3 isolates were found in sheep milk. Moreover, 4,3 and 4 isolates were recovered from yoghurt, pasteurized milk and fermented pickles, respectively. Screening of all isolates of LAB for antimicrobial activity revealed that the highest antimicrobial activities were against A. niger, Penicillium. sp., A. flavus (Table 1; Figures 1 and 2), A. ochraceus and Fusarium sp. No activity was observed against $A$. ochraceus and Fusarium porotrichoides (Table 1).

The isolate $\mathrm{S}_{2}$ was the most active isolate and it was characterized and identified through physiological and biochemical tests. The selected isolate L. bulgaricus $\mathrm{S}_{2}$ was tested against different toxigenic fungi (Alternaria sp., Trichosporon mycotoxinivorans and Cladosporium sp.) using well diffusion method (Table 2) according to Harris et al., (1989). The result in table (3) shows that the inhibitory agent of the selected isolate inhibited the fungal growth and spore formation of A. flavus. Scanning electron micrographs revealed structural changes in the morphology of A. flavus during any of the inhibitory experiments (Figures 3 and 4). The treated conidiophores had rough surface and was distorted and the spores appeared with normal shape in control A. flavus compared to treated cells which was elongated and appeared hollow and quantity of aflatoxins production was decreased (Figure 5). 
Nearly $25 \%$ of the European diet and $60 \%$ of the diet in many developing countries consist of fermented foods (Stiles, 1996). In addition, poultry for human consumption is generally fed on cereals or their products (Pinho and Furlong, 2000). Arqués et al., (2015) studied antimicrobial activity of lactic acid bacteria in dairy products and gut and their effect on pathogens.

There was a predominance of Aspergillus species during storage period of coffee beans (Arqués et al., 2015). Therefore, growth of the fungus in cereal crops could affect humans not only after consumption of infected cereals, but also after chicken consumption. In addition, the presence of toxigenic molds represents a potential risk of mycotoxin contamination especially while considering the worldwide increased use of herbal products as alternative medicine (Bugno et al., 2006).

Inhibition of mycotoxigenic fungi is necessary in order to avoid toxin formation in food and feed. According to our results, natural control of the microflora could be realized by beneficial microorganisms. The number of publications on antifungal LAB is still low (Schnürer and
Magnusson, 2005). LAB produce a variety of antimicrobial compounds. Various mechanisms have been suggested to be responsible for the inhibitory effects of the bacteria on fungal growth, such as nutritional competition, secondary metabolites, $\mathrm{pH}$ or combinations of these mechanisms (El-Nezami et al., 2002). L. acidophilus and Bifidobacterium animalis strains are able to detoxify the mycotoxins. Both species can be used for the production of probiotic fermented foods. Therefore, our findings may contribute to the development of strategies for the detoxification of contaminated plant derived products with these toxins by use of LAB (Fuchs, 2008).

Other authors have suggested that aflatoxin biosynthesis was inhibited by LAB but that the bacteria were not efficient enough to remove aflatoxin from the medium (Thyagaraja and Hosono, 1994). Our studies confirm previous studies demonstrating the inhibitory activity by LAB against a mycotoxin-producing fungus. $L$. bulgaricus $\mathrm{S}_{2}$ isolated from sheep milk and selected for its technological properties showed highest fungal inhibition of the microorganisms assayed.

Table.1 Screening of the recovered bacterial isolates for antimicrobial activity against some tested fungi using modified overlay method

\begin{tabular}{|c|c|c|c|c|c|}
\hline \multirow{2}{*}{$\begin{array}{c}\text { Isolate } \\
\text { code }\end{array}$} & \multicolumn{5}{|c|}{ Mean diameter of inhibition zone (mm) \pm SD } \\
\cline { 2 - 6 } & A. niger & A. ochraceus & A. flavus & Penicillium sp. & $\begin{array}{c}\text { Fusarium } \\
\text { sporotrichoides }\end{array}$ \\
\hline $\mathbf{H}_{\mathbf{1}}$ & $10.0 \pm 2.0$ & $0.0 \pm 0.0$ & $18.0 \pm 2.6$ & $7.6 \pm 1.5$ & $0.0 \pm 0.0$ \\
\hline $\mathbf{H}_{\mathbf{2}}$ & $16.3 \pm 2.3$ & $0.0 \pm 0.0$ & $9.0 \pm 1.0$ & $19.3 \pm 1.1$ & $0.0 \pm 0.0$ \\
\hline $\mathbf{H}_{\mathbf{3}}$ & $24.6 \pm 6.4$ & $0.0 \pm 0.0$ & $23.3 \pm 3.5$ & $18.3 \pm 2.0$ & $0.0 \pm 0.0$ \\
\hline $\mathbf{H}_{\mathbf{4}}$ & $0.0 \pm 0.0$ & $0.0 \pm 0.0$ & $0.0 \pm 0.0$ & $0.0 \pm 0.0$ & $0.0 \pm 0.0$ \\
\hline $\mathbf{H}_{\mathbf{5}}$ & $0.0 \pm 0.0$ & $0.0 \pm 0.0$ & $0.0 \pm 0.0$ & $0.0 \pm 0.0$ & $0.0 \pm 0.0$ \\
\hline $\mathbf{H}_{\mathbf{6}}$ & $0.0 \pm 0.0$ & $0.0 \pm 0.0$ & $0.0 \pm 0.0$ & $0.0 \pm 0.0$ & $0.0 \pm 0.0$ \\
\hline $\mathbf{H}_{\mathbf{7}}$ & $15.6 \pm 4.0$ & $0.0 \pm 0.0$ & $19.3 \pm 5.1$ & $8.0 \pm 2.6$ & $0.0 \pm 0.0$ \\
\hline $\mathbf{S}_{\mathbf{1}}$ & $8.0 \pm 1.0$ & $0.0 \pm 0.0$ & $2.6 \pm 1.1$ & $2.3 \pm 0.5$ & $0.0 \pm 0.0$ \\
\hline $\mathbf{S}_{\mathbf{2}}$ & $34.0 \pm 4.5$ & $0.0 \pm 0.0$ & $24.6 \pm 0.5$ & $29.0 \pm 1.0$ & $0.0 \pm 0.0$ \\
\hline $\mathbf{S}_{\mathbf{3}}$ & $9.3 \pm 0.5$ & $0.0 \pm 0.0$ & $12.6 \pm 2.0$ & $3.0 \pm 1.7$ & $0.0 \pm 0.0$ \\
\hline $\mathbf{Y}_{\mathbf{1}}$ & $0.0 \pm 0.0$ & $0.0 \pm 0.0$ & $0.0 \pm 0.0$ & $0.0 \pm 0.0$ & $0.0 \pm 0.0$ \\
\hline $\mathbf{Y}_{\mathbf{2}}$ & $3.6 \pm 1.5$ & $0.0 \pm 0.0$ & $2.6 \pm 0.5$ & $1.6 \pm 0.5$ & $0.0 \pm 0.0$ \\
\hline $\mathbf{Y}_{\mathbf{3}}$ & $0.0 \pm 0.0$ & $0.0 \pm 0.0$ & $0.0 \pm 0.0$ & $3.3 \pm 0.5$ & $0.0 \pm 0.0$ \\
\hline $\mathbf{Y}_{\mathbf{4}}$ & $3.6 \pm 0.5$ & $0.0 \pm 0.0$ & $3.0 \pm 1.7$ & $0.0 \pm 0.0$ & $0.0 \pm 0.0$ \\
\hline $\mathbf{L}_{\mathbf{1}}$ & $0.0 \pm 0.0$ & $0.0 \pm 0.0$ & $0.0 \pm 0.0$ & $1.3 \pm 0.5$ & $0.0 \pm 0.0$ \\
\hline $\mathbf{L}_{\mathbf{2}}$ & $0.0 \pm 0.0$ & $0.0 \pm 0.0$ & $0.0 \pm 0.0$ & $0.0 \pm 0.0$ & $0.0 \pm 0.0$ \\
\hline $\mathbf{L}_{\mathbf{3}}$ & $0.0 \pm 0.0$ & $0.0 \pm 0.0$ & $2.3 \pm 0.5$ & $0.0 \pm 0.0$ & $0.0 \pm 0.0$ \\
\hline $\mathbf{F}_{\mathbf{1}}$ & $0.0 \pm 0.0$ & $0.0 \pm 0.0$ & $0.0 \pm 0.0$ & $0.0 \pm 0.0$ & $0.0 \pm 0.0$ \\
\hline $\mathbf{F}_{\mathbf{2}}$ & $0.0 \pm 0.0$ & $0.0 \pm 0.0$ & $0.0 \pm 0.0$ & $0.0 \pm 0.0$ & $0.0 \pm 0.0$ \\
\hline $\mathbf{F}_{\mathbf{3}}$ & $0.0 \pm 0.0$ & $0.0 \pm 0.0$ & $0.0 \pm 0.0$ & $0.0 \pm 0.0$ & $0.0 \pm 0.0$ \\
\hline $\mathbf{F}_{\mathbf{4}}$ & $2.6 \pm 1.1$ & $0.0 \pm 0.0$ & $5.3 \pm 0.5$ & $0.0 \pm 0.0$ & $0.0 \pm 0.0$ \\
\hline
\end{tabular}

$\mathrm{H}_{1}$ to $\mathrm{H}_{7}$ : Human Milk; $\mathrm{S}_{1}$ to $\mathrm{S}_{3}$ : Sheep Milk; $\mathrm{Y}_{1}$ to $\mathrm{Y}_{4}$ : Yoghurt; $\mathrm{L}_{1}$ to $\mathrm{L}_{3}$ : Pasteurized Milk; $\mathrm{F}_{1}$ to $\mathrm{F}_{4}$ : Fermented Pickle. 
Table. 2 Screening of the selected bacterial isolate $S_{2}$ for antimicrobial activity against some toxigenic fungi using well-diffusion method

\begin{tabular}{|c|c|}
\hline The tested toxigenic fungi & Mean diameter of inhibition zone (mm) \pm SD \\
\hline Aspergillus niger & $13.6 \pm 1.5$ \\
\hline Aspergillus flavus & $19.0 \pm 1.0$ \\
\hline Penicillium $\mathrm{sp}$. & $15.3 \pm 4.5$ \\
\hline Alternaria sp. & $28.6 \pm 1.1$ \\
\hline Trichosporon mycotoxinivorans & $22.3 \pm 2.0$ \\
\hline Cladosporium $\mathrm{sp}$. & $17.3 \pm 1.1$ \\
\hline
\end{tabular}

Table.3 Effect of the active material on number of colony of Aspergillus flavus

\begin{tabular}{|c|c|}
\hline \multicolumn{2}{|c|}{ Effect of the active material on number of spore/ml } \\
\hline Normal & Treated \\
\hline $2 \times 10^{4} \pm 3.6$ & $2.2 \times 10^{2} \pm 1.0^{*}$ \\
\hline
\end{tabular}

*: Significant at $p$-value $\leq 0.05$

Fig.1 Antimicrobial activity of the isolated bacterium S2 against toxigenic fungi using modified overlay method

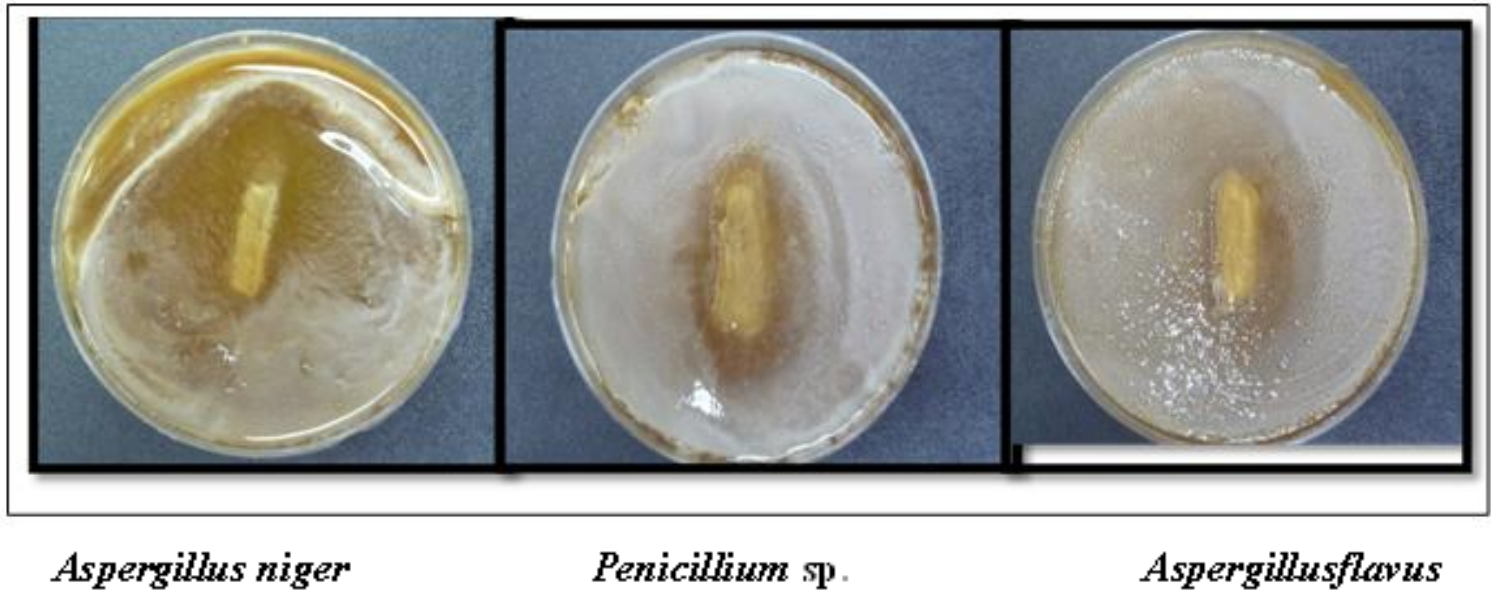

Fig.2 Antimicrobial activity of isolated bacterium $\mathrm{H} 3$ against toxigenic fungi using modified overlay method
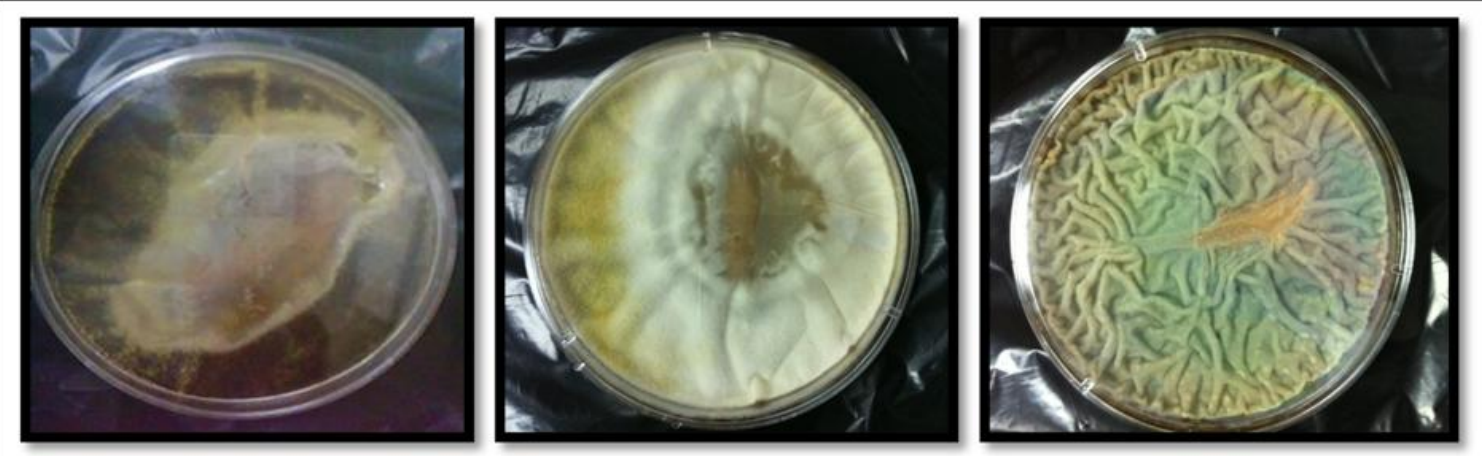
Fig.3 Aspergillus flavus (conidiophores and spores) under scanning electron microscope (A and B) with different magnification after 48 hours at $28^{\circ} \mathrm{C}$ (untreated)

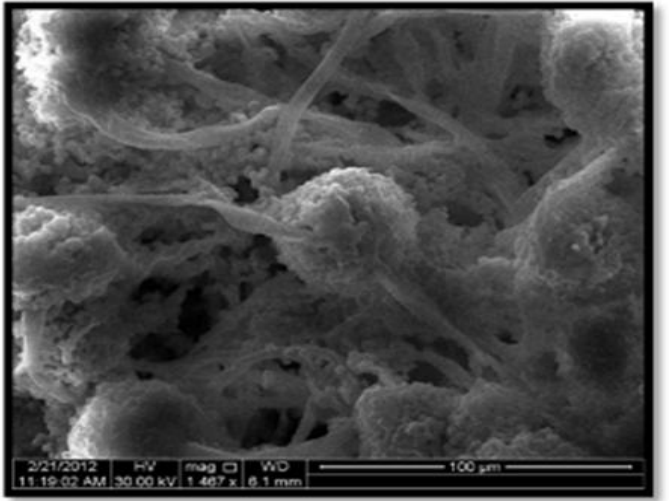

A

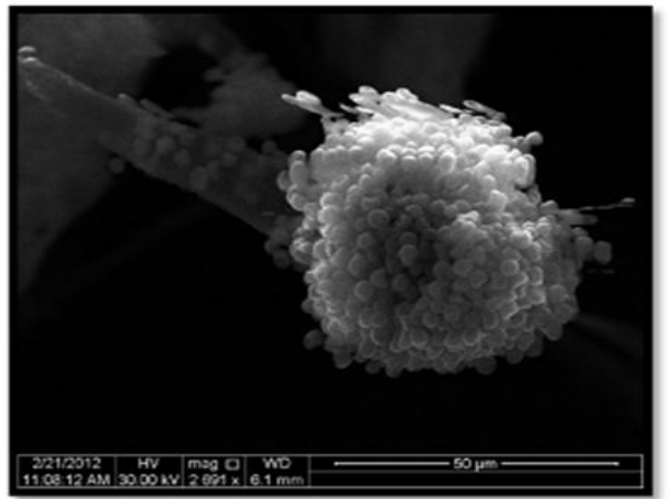

B

Fig.4 Effect of antimicrobial agent on morphology of Aspergillus flavus (conidiophores and spores) under scanning electron microscope (A and B) after 48 hours at $28^{\circ} \mathrm{C}$

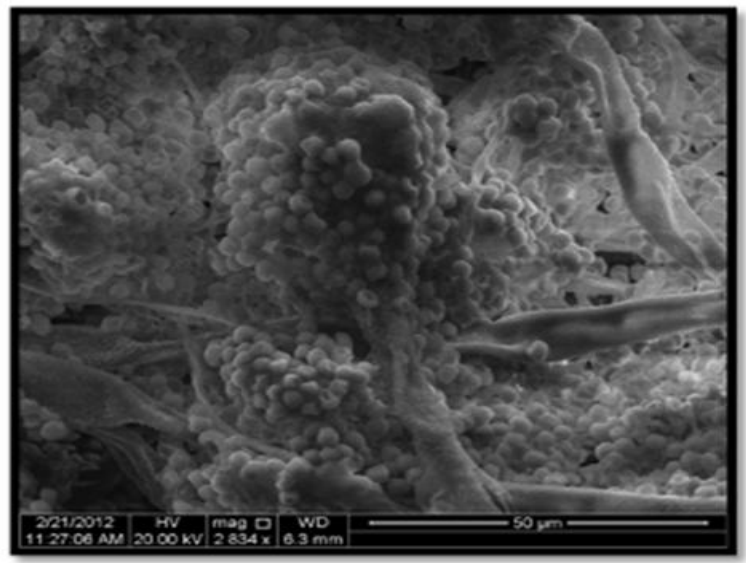

A

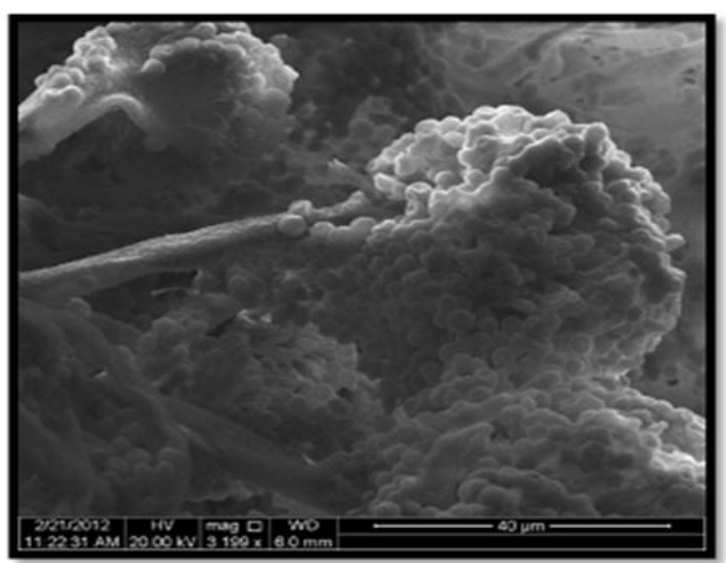

B

Fig.5 Aflatoxin detection at UV254 in untreated and treated Aspergillus extract using UV light

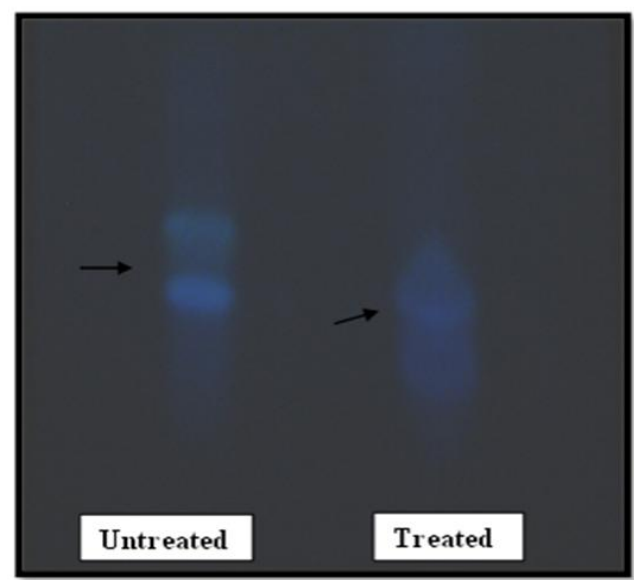


Probiotics are usually isolated from the gastrointestinal tract of humans and animals. The search of probiotics in human milk was a recent field of research, as the existence of the human milk microbiome was discovered only about a decade ago; Quilodrán-Vega et al., (2016) isolated several lactic acid bacteria from swine milk and evaluated them for their potential as probiotics, they showed that $L$. curvatus TUCO-5E is a good candidate to study in vivo the protective effect of probiotics against intestinal infection and damage induced by Salmonella infection in the porcine host (Quilodrán-Vega et al., 2016).

The inhibitory activity of lactobacilli against molds could be due to different factors. It is worthy to mention that the obtained 21 bacterial isolates were screened for their antimicrobial activity against some mycotoxigenic fungi using modified overlay method described by Magnusson and Schnurer (2000). Onilude et al., (2005) and Munoz et al., (2010) used the modified overlay method to detect the antimicrobial activity of lactic acid against aflatoxinproducing fungi.

Temperature and incubation period were essential factors that modulate LAB growth and significantly affect the amounts of antifungal metabolites produced by LAB (Batish et al.,1997) The studies carried out by Sathe et al.,(2007) demonstrated that antifungal activity of $L b$. plantarum CUK501 was maximal at $30^{\circ} \mathrm{C}$, when the culture was at the end of its logarithmic phase. Batish et al., (1990) observed that the antifungal activity of a $L$. acidophilus strain was maximal at $30^{\circ} \mathrm{C}$ after $48 \mathrm{~h}$ incubation, whereas increasing the incubation period resulted in a lower antifungal activity. These "antimycotoxinogenic" metabolites could also be produced during LAB growth (Dalié, et al., 2010). Growth, cell numbers, morphological characters and toxin production of A. flavus, treated with $\mathrm{S}_{2}$ filtrate were determined and compared to that obtained for untreated Aspergillus (control). The growth and the number of the cells were decreased by the antimicrobial agent $S_{2}$. The fungal morphology was changed and the quantity of aflatoxin production was decreased. Our results are in agreement with those previously observed by Onilude $e t$ al., (2005) that show the lactic acid bacteria isolates to have effect on the different Aspergillus species prior to the sporulation of the latter. Lactobacillus fermentum RS2 was observed to exhibit maximum inhibition on mycelial development for most of the Aspergillus species while Lactobacillus spp. had the lowest. Thyagaraja and Hosono (1994) suggested that aflatoxin biosynthesis was inhibited by LAB but the bacteria were not efficient enough to remove aflatoxin from the medium. The interaction between mycotoxin producing fungi and other microorganisms is a common phenomenon in nature that can affect fungal growth and/or production of mycotoxins (Thyagaraja and Hosono, 1994).

The use of antifungal LAB instead of chemical preservatives would enable the food industry to produce organic food without addition of chemical substances. In addition to the already known excellent properties of LAB they could enhance the nutritional value and prolong conservation of food (Hassan and Bullerman, 1997).

\section{Acknowledgements}

We thank the staff of the laboratories and the electronic microscope unit of King Abdul Aziz University in Saudi Arabia for their cooperation during this study.

\section{References}

Pitt, J.I., Hocking, A.D. Fungi and Food Spoilage. 2nd ed. Blackie Academic and Professional, Cambridge, 1997.

Strom, K., Sjogren, J., Broberg, A., Schnurer, J. Lactobacillus plantarum MiLAB 393 produces the antifungal cyclic dipeptides cyclo (1-Phe-1Pro) and cyclo (1-Phe-trans-4-OH-1-Pro) and 3phenyllactic acid. Appl. Environ. Microbiol. 2002; 68: 4322-4327.

Aguirre, M., Collins, M. D. Lactic acid bacteria and human clinical infection. J. appl. Bacteriol. 1993; 75: 95-107.

Holzapfel, W. H., Haberer, P., Geisen, R., Björkroth, J., Schillinger, U. Taxonomy and important features of probiotic microorganisms in food nutrition. Am. J. Clin. Nutr. 2001; 73: 365S-373S.

Singh, P., Prakash, A. Screening of Lactic Acid Bacteria for Antimicrobial Properties Against Listeria monocytogenes isolated from Milk Products at Agra Region. Internet Journal of Food Safety. 2009; 11, p. 81-87.

Muñoz, R, Arena, M. E., Silva, J., González, S. N. Inhibition of mycotoxin producing Aspergillus nomius VSC 23 by lactic acid bacteria and Saccharomyces cerevisiae. Brazilian Journal of Microbiology. 2010; 41: 1019-1026.

Onilude, A. A., Fagade, O. E., Bello, M. M., Fadahunsi. I. F. Inhibition of aflatoxin-producing aspergilli by lactic acid bacteria isolates from indigenously 
fermented cereal gruels. African Journal of Biotechnology. 2005; 4(12): 1404-1408.

Magnusson, J., Strom, K., Roos, S., Sjogren, J., Schnurer, J. Broad and complex antifungal activity among environmental isolates of lactic acid bacteria. FEMS Microbiology Letters 2003; 219: 129-135.

El-Nezami, H.; Polychronaki, N., Salminen, S., Mykkanen, H. Binding rather than metabolism may explain the interaction of two food grade Lactobacillus strains with zearalenone and its derivative alpha zearalenol. App. Environ. Microbiol. 2002;68: 3545-3549.

Magnusson, J., Schnurer, J. Lactobacillus coryniformis subsp. Coryniformisstrain Si3 produces a broadspectrum proteinaceous antifungal compound Appl. Environ. Microbiol. 2000; 67: 1-5.

Holt, J. G., Krieg, N. R., Sneath, P. H.A., Staley, J. T., Williams, S. T. Bergey's Manual of Determinative Bacteriology. $9^{\text {th }}$ ed. Eds. (Williams and Wilkins). Baltimore. USA. 1994.

Sharpe, M. E., Fryer, T. F., Smith, D, G. Identification of Lactic Acid Bacteria. In: Identification Methods for Microbiologists, E. M. Gibbs, F. A. Skinner (Eds), London: Academic Press 1979, 233-259.

Harris, L. J., Daeschel, M. A., Stiles, M. A. Antimicrobial activity of Lactic acid bacteria against Listeria monocytogenes. J. Food Prot. 1989; 52: 384-387.

Stiles, M.E. Bio-preservation by lactic acid bacteria. Antonie van Leeuwenhoek 1996; 70, 331-345.

Pinho, B.H., Furlong, E.B. The occurrence of molds, yeasts and mycotoxins in pre-cooked pizza dough sold in Southern Rio Grande do Sul. Braz. J. Microbiol. 2000; 31: 99-102.

Arqués, J.L., Rodríguez, E., Langa, S., Landete, J.M., and Medina, M. Antimicrobial Activity of Lactic Acid Bacteria in Dairy Products and Gut: Effect on Pathogens. BioMed Research International. 2015; 9 pages.

Bugno, A., Buzzo Almodovar, A.A., Caldas Pereira, T., Andreoli Pinto, T.J., Sabino M. Occurrence of toxigenic fungi in herbal drugs. Braz. J. Microbiol. 2006; 37: 47-51.

Schnürer, J., Magnusson, J. Antifungal lactic acid bacteria as biopreservatives. Trends Food Sci. and Technol. 2005;16: 70-78.

Fuchs, S., Sontag, G., Stidl, R., Ehrlich, V., Kundi, M., Knasmüller, S. Detoxification of patulin and ochratoxin A, two abundant mycotoxins, by lactic acid bacteria. Food Chem. Toxicol. 2008; 46: 1398-1407.

Thyagaraja, N, Hosono, A. Binding properties of lactic acid bacteria from 'Idly' towards food-borne mutagens. Food Chem. Toxicol.1994; 32: 805809.

Quilodrán-Vega, SR. Villena, J. Valdebenito, J. Salas, MJ. Parra, C. Ruiz, A. Kitazawa, H, García, A. Isolation of lactic acid bacteria from swine milk and characterization of potential probiotic strains with antagonistic effects against swineassociated gastrointestinal pathogens. Can J Microbiol. 2016; 62(6):514-24.

Batish, V.K., Roy, U., Lal, R., Grover, S. Antifungal attributes of lactic acid bacteria - A review. Crit. Rev. Biotechnol. 1997; 17: 209-225.

Sathe, S. J., Nawani, N. N., Dhakephalkar, P. K., Kapadnis, B. P. Antifungal lactic acid bacteria with potential to prolong shelf-life of fresh vegetables. J. Appl. Microbiol. 2007; 103: 26222628.

Batish, V.K., Lal, R., Grover, S. Studies of environmental and nutritional factors on production of antifungal substance by Lactobacillus acidophilus. R. Food Microbiol. 1990; 7: 199-206.

Dalié D.K.D., Deschamps A.M., Richard-Forget, F. Lactic acid bacteria - Potential for control of mould growth and mycotoxins. Food Control. 2010; 21(4): 370-380.

Hassan, G., Bullerman, L. B. Anti-aflatoxigenic activity of Lactobacillus casei pseudoplantarum. Int. J. FoodMicrobiol. 1997; 34: 131-143.

\section{How to cite this article:}

Wadad M. Al-Haik, Ali Mohammed Abdullah Bawazir, Magda Mohammad Aly, Ahmed M. Al-Haddad and Manjula Shantaram. 2017. Antimicrobial Activity of Lactic Acid Bacteria against Toxigenic Fungi. Int.J.Curr.Res.Aca.Rev. 5(11), 12-18. doi: https://doi.org/10.20546/ijcrar.2017.511.003 